\title{
The effects of long-lasting hypoglycemia on male reproductive organs in rats
}

\author{
Taiki Kobayashi, Junichi Namekawa, Takasumi Shimomoto, Mari Yasui, Takeshi lijima, \\ Yasuhiro Itano, Daishiro Miura and Yoshinori Kasahara
}

Teijin Pharma Limited, Pharmaceutical Development Research Laboratories

4-3-2, Asahigaoka, Hino, Tokyo 191-8512, Japan

(Received January 5, 2015; Accepted August 12, 2015)

\begin{abstract}
Glucose has an important role in spermatogenesis. Nevertheless there are few reports in which the effects of long-lasting hypoglycemia on male reproductive organs have been evaluated. Therefore, insulin was administered subcutaneously at 100,200 , and $400 \mathrm{IU} / \mathrm{kg}$ to male rats twice a day for one month. This treatment regimen produced plasma glucose levels that rapidly decreased after treatment, with decreased glucose levels lasting for several hours after each administration on the first and final treatment days. During the treatment period, no abnormalities in clinical signs or body weight were observed. No statistically significant differences were noted in the weights of testes, epididymides, prostates and seminal vesicles, or pituitary glands. Histopathological examination revealed that the insulintreated animals exhibited degeneration of seminiferous tubules in the testes and exfoliation of germ cells in the lumens of epididymides as a secondary change related to the testicular lesions. The incidences of the histopathological findings were found to be proportional to insulin dose. Sperm analysis of the group receiving the highest dosage indicated that the sperm concentration tended to decrease and the incidences of sperm malformations tended to increase. Our results suggest that long-lasting hypoglycemia affects male reproductive organs in rats.
\end{abstract}

Key words: Hypoglycemia, Insulin, Testis, Sperm, Germ cell, Reproductive organs

\section{INTRODUCTION}

Many factors have been reported to affect the testis, including malnutrition. For example, deficiencies in zinc, Vitamin A, and Vitamin E are known to induce damage to the testis (Sobhon et al., 1979; Livera et al., 2002; Bensoussan et al., 1998; Mason et al., 1982; Merker and Günther, 1997). From a nutrition perspective, glucose is known to play an important role in energy metabolism in the testis. Germ cells use glucose and lactate, which is converted from glucose and is supplied by Sertoli cells (Rato et al., 2012; Bajpai et al., 1998; Boussouar and Benahmed, 2004; Jutte et al., 1982; Robinson and Fritz, 1981). Nevertheless, there are few reports evaluating the effects of glucose deficiency (hypoglycemia) on the testis.

Though there are only a few reports, histopathological examination of the testes has been conducted under hypoglycemic conditions, caused by administration of insulin or tolbutamide to fasted rats (Mancine et al., 1960). The results showed the presence of sloughing of germ cells, intracellular vacuoles, pyknosis, and multinucleated masses of germ cells in the seminiferous epithelium. However, the possibility that these lesions were secondary changes due to the deterioration of the general condition of the animals cannot be excluded, because the hypoglycemia in the study by Mancine et al. (1960) was so severe as to induce hypoglycemic coma. In addition, the plasma glucose levels were not reported in detail.

The purpose of this study was to evaluate the effects of long-lasting hypoglycemia on male reproductive organs without adversely affecting clinical signs and body weight. Male rats were treated subcutaneously with insulin twice a day at $4 \mathrm{hr}$ intervals for a month. Using this treatment regimen, we aimed to avoid abnormal clinical signs and body weight changes while maintaining longlasting hypoglycemia. Moreover, by conducting histopathological and sperm analysis after insulin treatment,

Correspondence: Taiki Kobayashi (E-mail: tai.kobayashi@teijin.co.jp) 
we evaluated the effects of long-lasting hypoglycemia on male reproductive organs.

\section{MATERIALS AND METHODS}

\section{Animal}

Sprague Dawley male rats $[\mathrm{Crl}: \mathrm{CD}(\mathrm{SD}), 4.5$ weeks old] were purchased from Charles River Laboratories Japan, Inc. (Kanagawa, Japan). They were quarantined and acclimatized for 12 days upon arrival at our animal facility. The rats were housed individually in suspended stainless steel wire mesh cages and provided ad libitum access to CLEA Rodent Diet CE-2 (CLEA Japan, Inc., Tokyo, Japan) and water. The animal room was maintained at $24 \pm 2{ }^{\circ} \mathrm{C}, 55 \pm 15 \%$ relative humidity, with a 12-hr light/dark regime and an air exchange rate of 10 to 20 times per hour. The animals were randomly allocated to 4 groups of 20 animals for histopathological examination and sperm analysis (toxicity groups) and 6 animals for measurements of plasma glucose levels (satellite groups). Software (StatLight group allocation, Yukms Co., Ltd, Kanagawa, Japan) was used for group allocation and animals were numbered according to the order fixed randomly by the software. All animals were used for histopathological evaluation because this evaluation was primary endpoint of this study. By the same reason, all animals were used for sperm analysis referring to following sentence in S5(R2) guideline of International Conference on Harmonisation of Technical Requirements for Registration of Pharmaceuticals for Human Use (ICH); "evaluation of between 16 to 20 litters for rodents and rabbits tends to provide a degree of consistency between studies" (ICH, 2005). Clinical signs, body weight and organ weight were secondary endpoints. Therefore, although the clinical signs were observed in all animals, 10 animals, which were considered to be enough from the viewpoint of statistical power, were used for measurement of body and organ weights referring to Organisation for Economic Co-operation and Development (OECD) Guideline 407 in which at least 10 animals were needed at each dose level for "Repeated Dose 28-day Oral Toxicity Study in Rodents" (OECD, 2008). Statistical analysis method was written in "Statistics" in detail. This study was conducted in compliance with the "Animal Experiment Regulations" and "Regulations on Animal Euthanasia" of the Institute for Bio-medical Research, Teijin Pharma Limited.

\section{Dosing}

The insulin used in this study was Novolin R $100 \mathrm{IU} / \mathrm{mL}$ (Novo Nordisk Pharma Ltd., Tokyo, Japan), which was diluted with physiological saline to 10,20 , and $40 \mathrm{IU} /$ $\mathrm{mL}$. Insulin was administered subcutaneously at the back of the neck at 100, 200, and $400 \mathrm{IU} / \mathrm{kg}$ (volume: $5 \mathrm{~mL} / \mathrm{kg}$ ) twice a day (b.i.d.), with $4 \mathrm{hr}$ between doses. In the toxicity groups, half of the animals in each group were treated for 28 days (necropsy conducted on day 29) and the remaining animals were treated for 29 days (necropsy conducted on day 30 ). In the satellite groups, the animals were treated for 28 days. Control animals were treated with physiological saline in the same manner.

\section{Blood sampling}

Blood samples were obtained at various time points $(0,0.5,1,2,4,5,6,8$, and $24 \mathrm{hr})$ after the first administration of the first and last treatment days. Using heparin as an anticoagulant, blood was obtained from the tail vein. Repeated blood sampling of a group of 3 animals was used to obtain the mean values for the $0,1,4,6$, and $24 \mathrm{hr}$ time points, while a separate group of 3 animals was used to collect the data for the $0.5,2,5$, and $8 \mathrm{hr}$ time points. Plasma glucose levels were measured using the hexokinase method with a 7180 Clinical Analyzer (Hitachi High-Technologies Corporation, Tokyo, Japan).

\section{Clinical signs and body weight}

Observations of clinical signs were performed daily throughout the treatment period. Measurements of body weight were performed on the day before treatment (day 0 ) and days 3, 7, 10, 14, 17, 21, 24, and 28. Body weight was also measured before necropsy to calculate the relative organ weights.

\section{Post-mortem examination and organ weights}

Half of the animals in each toxicity group were necropsied on day 29 and the remainder on day 30 . All the animals were fasted for approximately $16 \mathrm{hr}$ (beginning approximately $4 \mathrm{hr}$ after receiving the final dose prior to necropsy) except for the $400 \mathrm{IU} / \mathrm{kg}$ b.i.d. animals. In the $400 \mathrm{IU} / \mathrm{kg}$ b.i.d. group, 5 out of 10 fasted animals were found dead on the day of necropsy (day 29). Thus, fasting the remaining 10 animals on the day before necropsy (day 29) was canceled. The remaining live animals in the toxicity groups were weighed on the day of necropsy and euthanized by exsanguination under anesthesia by an intraperitoneal injection of sodium pentobarbital. External appearance, and internal organs and tissues were observed macroscopically in all the animals. Thereafter, the testes, epididymides, prostates and seminal vesicles (with coagulating glands), and pituitary glands were weighed. The bilateral testes and epididymides were weighed separately and the total weights were calculated. The relative organ 
The effects of long-lasting hypoglycemia on male reproductive organs

weights were calculated using the body weight on the day of necropsy.

\section{Histopathological examination}

The following organs and tissues in all toxicity group animals, excluding the dead animals, were immersionfixed in 10\% neutral buffered formalin: epididymides, prostates and seminal vesicles (with coagulating glands), and pituitary glands. The right epididymides were fixed after semen was collected from the caudal region. The testes in all toxicity group animals were immersion-fixed in Bouin's solution. The tissue specimens were prepared by sectioning the paraffin-embedded tissues, stained with hematoxylin and eosin, and examined microscopically.

\section{Sperm analysis}

At necropsy, semen was collected from the right cauda epididymis and diluted with Dulbecco's modified Eagle medium. The semen dilutions were incubated for $1 \mathrm{hr}$ at $37^{\circ} \mathrm{C}$ and subsequently stored at $4^{\circ} \mathrm{C}$ until analysis. Sperm concentration was obtained by counting the number of sperm in the diluted samples using a light microscope and a Burker-Turk hemocytometer. Sperm morphology was assessed by preparing dried sample smears on glass slides and staining with Giemsa stain. A total of 200 sperms from each animal were evaluated microscopically and the incidences of sperm malformations were calculated in each region (head, neck, middle piece, and tail).

Semen was not collected from the 5 dead animals in the $400 \mathrm{IU} / \mathrm{kg}$ b.i.d. group. Sperm aggregation was observed in 4 of the 15 sperm samples from the $400 \mathrm{IU} / \mathrm{kg}$ b.i.d. group, and in 5 of the 20 sperm samples in the $200 \mathrm{IU} / \mathrm{kg}$ b.i.d. group. The aggregates were likely caused during sample processing. Thus, these samples were excluded from the statistical analyses.

\section{Statistics}

Differences in body weight, organ weights, and sperm concentration were evaluated using Dunnett's test following Bartlett's test. Analysis of the incidences of sperm malformations was evaluated using the mean rank test of the Dunnett type. The body and organ weights of 10 animals in each group were selected from the lowest animal number, as assigned randomly by the StatLight software, and subjected to statistical analysis. For the sperm concentration and the incidences of sperm malformations all animals were subjected to statistical analysis. Organ weights, sperm concentration, and the incidences of sperm malformations in the $400 \mathrm{IU} / \mathrm{kg}$ b.i.d. group were not statistically analyzed because many of the $400 \mathrm{IU} / \mathrm{kg}$ b.i.d. animals were sacrificed under different conditions. The signifi- cance level was $5 \%$ for all tests.

\section{RESULTS}

\section{Clinical signs and body weight}

Throughout the treatment period, no insulin-related clinical signs were noted in any of the groups. Body weight was measured twice a week in the treatment groups and was not significantly different from that of the control group. In the $400 \mathrm{IU} / \mathrm{kg}$ b.i.d. group, half of 10 fasted animals were found dead on the day of necropsy. However, the non-fasted animals in the same group survived and did not show any insulin-related changes on the day of necropsy.

From these results it was confirmed that dosing scheme of this study did not induce the deterioration of the general condition.

\section{Plasma glucose levels}

Plasma glucose levels are shown in Fig. 1. Plasma glucose levels on the first and final treatment days rapidly decreased after the first insulin dose, with the lowered glucose levels lasting for several hours after each administration.

On the first treatment day, the mean plasma glucose levels of the control group were $128-155 \mathrm{mg} / \mathrm{dL}$. On the same day, the levels of the $100 \mathrm{IU} / \mathrm{kg}$ b.i.d. group decreased from 144 to $52 \mathrm{mg} / \mathrm{dL}$, the $200 \mathrm{IU} / \mathrm{kg}$ b.i.d. group from 140 to $44 \mathrm{mg} / \mathrm{dL}$, and the $400 \mathrm{IU} / \mathrm{kg}$ b.i.d. group from 138 to $40 \mathrm{mg} / \mathrm{dL}$. On the final treatment day, the levels of the control group were $122-152 \mathrm{mg} / \mathrm{dL}$. On the same day, the levels of the $100 \mathrm{IU} / \mathrm{kg}$ b.i.d. group decreased from 175 to $38 \mathrm{mg} / \mathrm{dL}$, the $200 \mathrm{IU} / \mathrm{kg}$ b.i.d. group from 207 to $35 \mathrm{mg} / \mathrm{dL}$, and the $400 \mathrm{IU} / \mathrm{kg}$ b.i.d. group from 228 to $30 \mathrm{mg} / \mathrm{dL}$.

From above results it was confirmed that dosing scheme of this study induced long-lasting hypoglycemia.

\section{Post-mortem examination and organ weights}

No insulin-induced macroscopic alterations were observed in the male reproductive organs. Small left testis was observed in one animal in the $200 \mathrm{IU} / \mathrm{kg}$ b.i.d. group as an incidental finding. Localized reddish discoloration on the stomach was observed in the fasted animals of the treatment groups. Additionally, fasted animals in the $400 \mathrm{IU} / \mathrm{kg}$ b.i.d. group exhibited smudges on the body surface, which were likely associated with their rapidly deteriorating condition or death caused by excess hypoglycemia.

Organ weights are shown in Table 1. No statistically significant differences were found in the absolute or rel- 

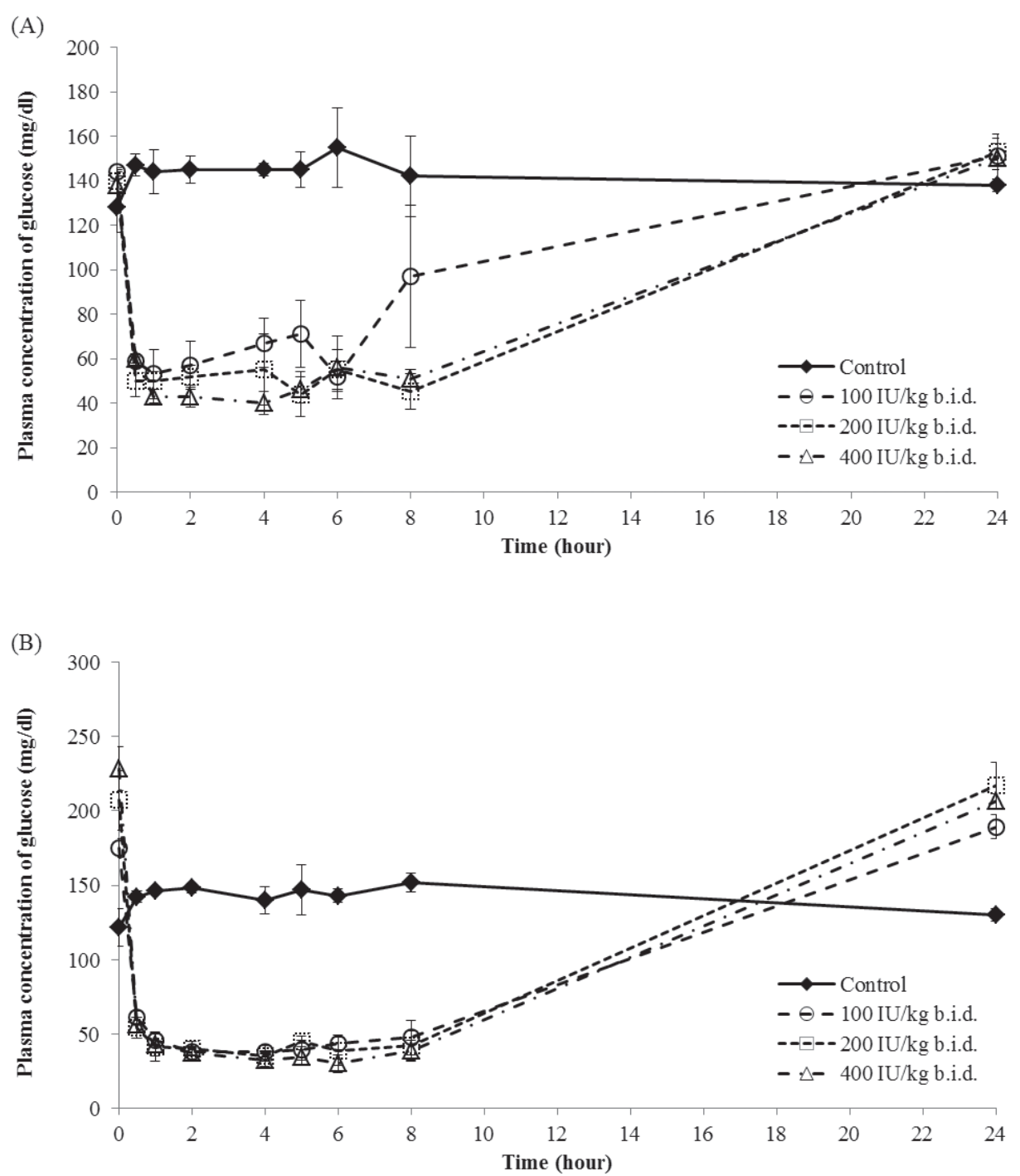

Fig. 1. Plasma glucose levels on the first (A) and final (B) treatment days. Insulin was administered twice a day with $4 \mathrm{hr}$ between doses and blood samples were obtained at $0,0.5,1,2,4,5,6,8$, and $24 \mathrm{hr}$ after first administration. The data are presented as the mean \pm S.D. $(n=3)$.

ative organ weights of testes, epididymides, prostates and seminal vesicles, and pituitary glands in the treatment groups (100 and $200 \mathrm{IU} / \mathrm{kg}$ b.i.d. groups) when compared with the control group. Moreover, organ weights of the $400 \mathrm{IU} / \mathrm{kg}$ b.i.d. group were not different from those of the control group.

\section{Histopathological examination}

Some animals in the 100,200 , and $400 \mathrm{IU} / \mathrm{kg}$ b.i.d. groups showed degeneration of seminiferous tubules in the bilateral testes (Figs. 2E to 2H). In a cross section of testis, the histopathological changes in a few adjoining seminiferous tubules were scattered but the substantial portion of the tubules was nearly normal. The tubules contained multinucleated giant cells (Figs. $2 \mathrm{~F}$ and $2 \mathrm{H}$ ), germ cells with eosinophilic cytoplasm and nuclear condensation (Fig. 2F), focal tubular vacuolation (Fig. 2G), disorganizations of germ cells, or spermatid retention. The animals in which the testicular change was observed also showed very slight exfoliation of germ cells in the lumens of the bilateral epididymides (Fig. 2I). The incidences of both histopathological abnormalities were pos- 
The effects of long-lasting hypoglycemia on male reproductive organs

Table 1. Organ weights.

\begin{tabular}{llcccc}
\hline Dose (IU/kg b.i.d.) & & 0 & 100 & 200 & $400^{\mathrm{a}}$ \\
\hline No. of animals & & 10 & 10 & 10 & 5 \\
\hline Testis $^{\mathrm{b}}$ & $(\mathrm{g})$ & $3.0357 \pm 0.3103$ & $3.1092 \pm 0.1979$ & $3.1954 \pm 0.2059$ & $3.0673 \pm 0.3192$ \\
& $(\%)^{\mathrm{c}}$ & $0.8447 \pm 0.0825$ & $0.7938 \pm 0.0774$ & $0.8107 \pm 0.0879$ & $0.8169 \pm 0.0967$ \\
Epididymis $^{\mathrm{b}}$ & $(\mathrm{g})$ & $0.8527 \pm 0.0910$ & $0.8524 \pm 0.0470$ & $0.8595 \pm 0.0606$ & $0.7835 \pm 0.0695$ \\
& $(\%)^{\mathrm{c}}$ & $0.2375 \pm 0.0264$ & $0.2172 \pm 0.0148$ & $0.2176 \pm 0.0189$ & $0.2080 \pm 0.0133$ \\
Prostate and seminal vesicles & $(\mathrm{g})$ & $1.8466 \pm 0.3032$ & $1.9201 \pm 0.2778$ & $2.0189 \pm 0.3038$ & $1.9803 \pm 0.4060$ \\
& $(\%)^{\mathrm{c}}$ & $0.5165 \pm 0.0998$ & $0.4867 \pm 0.0524$ & $0.5098 \pm 0.0743$ & $0.5247 \pm 0.0984$ \\
Pituitary gland & $(\mathrm{g})$ & $0.0097 \pm 0.0016$ & $0.0102 \pm 0.0011$ & $0.0105 \pm 0.0016$ & $0.0089 \pm 0.0007$ \\
& $(\%)^{\mathrm{c}}$ & $0.0027 \pm 0.0003$ & $0.0026 \pm 0.0002$ & $0.0026 \pm 0.0003$ & $0.0024 \pm 0.0001$ \\
\hline
\end{tabular}

Values are mean \pm S.D.

a : Data were not statistically analyzed.

$\mathrm{b}$ : The sum of right and left organ weights.

c: Ratio of organ weight to body weight (relative organ weight).
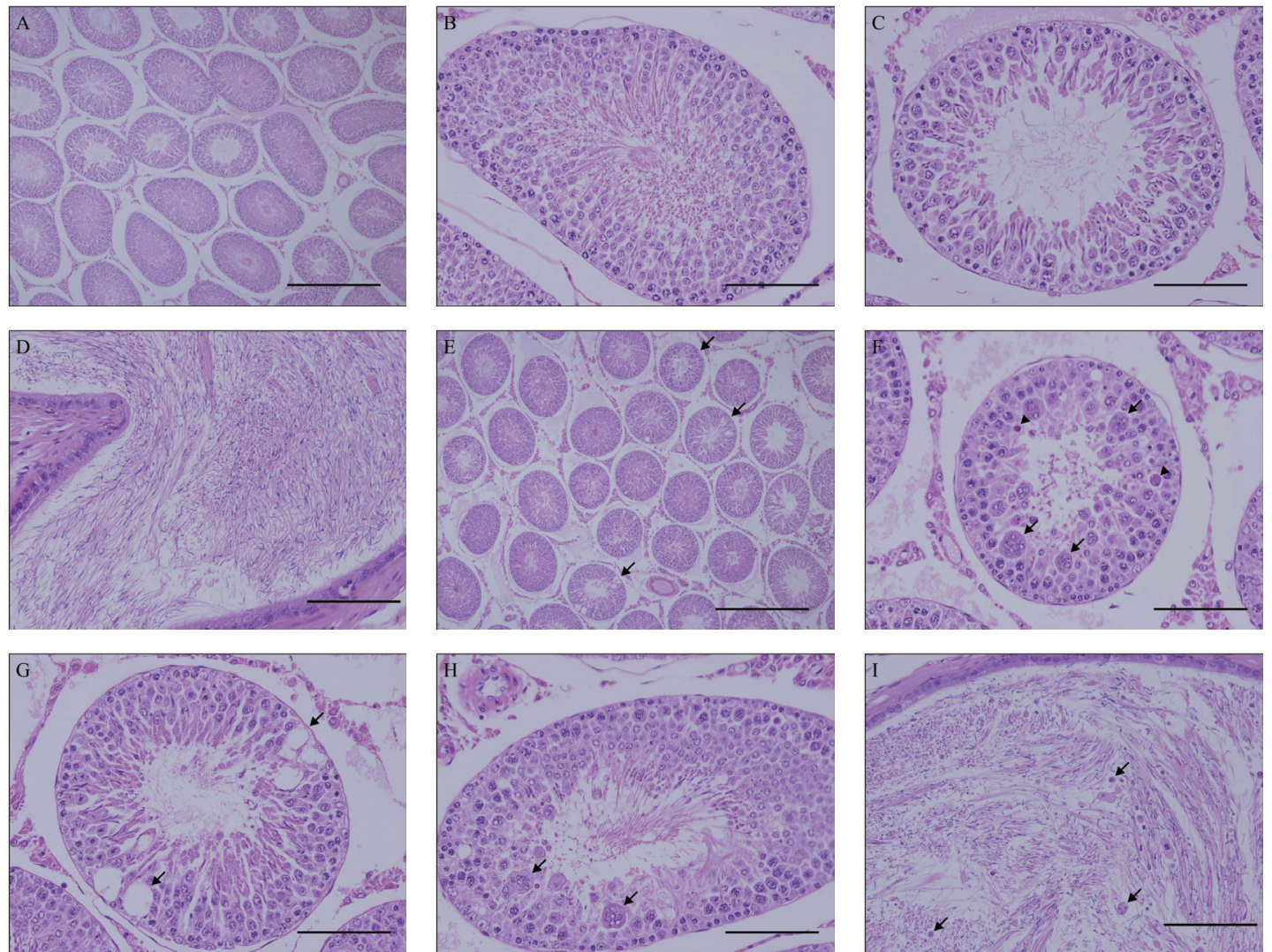

Fig. 2. Representative histopathological images (hematoxylin and eosin staining) of testes and epididymides. Images of a control testis at low (A) and high magnification (B and C), and an epididymis at low magnification (D). No abnormalities were observed in the control tissues. Images of a testis at low (E) and high magnification (F to $\mathrm{H}$ ), and an epididymis at low magnification (I) from an animal treated with $400 \mathrm{IU} / \mathrm{kg}$ b.i.d. insulin. Degenerated seminiferous tubules were observed sporadically (arrows in E). The tubules contained multinucleated giant cells (arrows in F and $\mathrm{H}$ ), germ cells with eosinophilic cytoplasm and nuclear condensation (arrowheads in F), focal tubular vacuolation (arrows in G), germ cell loss, and disorganization of the germ cells. The epididymis exhibited exfoliation of germ cells in the lumen (arrows in I). The scale bars in $\mathrm{A}$ and $\mathrm{E}$ represent $500 \mu \mathrm{m}$, and the scale bars in B to D and F to I represent $100 \mu \mathrm{m}$. 
itively correlated with insulin dose, and these abnormalities were not observed in the control group (Figs. 2A to 2D). The number of animals with the abnormalities at control, 100, 200, and $400 \mathrm{IU} / \mathrm{kg}$ b.i.d. groups were 0,1 , 2 , and 4 , respectively. In the $400 \mathrm{IU} / \mathrm{kg}$ b.i.d. group, these changes were observed in 2 fasted and 2 non-fasted animals.

\section{Sperm analysis}

The results of the sperm analysis are shown in Table 2. The sperm concentration and incidences of sperm malformations in the 100 and $200 \mathrm{IU} / \mathrm{kg}$ b.i.d. groups showed no statistically significant differences from the control group. However the $400 \mathrm{IU} / \mathrm{kg}$ b.i.d. group showed a tendency toward a decrease in the sperm concentration and an increase in the incidences of sperm malformations, compared with those in the control group.

\section{DISCUSSION}

During the treatment period, no insulin-related clinical signs were noted, such as coma, which was observed in a previous study (Mancine et al., 1960). Furthermore, the body weight during the treatment period did not change. The treatment regimen produced rapid decreases in plasma glucose levels after the first dose, with low glucose levels lasting for several hours after each administration. Hypoglycemia is clinically diagnosed when human plasma glucose levels are below $50 \mathrm{mg} / \mathrm{dL}$ (Bonds et al., 2010; Rosenstock et al., 2001; Yki-Järvinen et al., 2000). In this study plasma glucose levels in all the treatment groups decreased to about 50 or less, indicating the occurrence of a clinical hypoglycemic condition. On the final dosing day, there were no differences in the plasma glucose levels among all treatment groups until $8 \mathrm{hr}$ after administration of the first dose. However, deaths were observed only in the $400 \mathrm{IU} / \mathrm{kg}$ b.i.d. group dur- ing fasting for approximately $16 \mathrm{hr}$. Throughout the treatment period, no abnormal clinical signs and body weight changes were observed in all animals including the $400 \mathrm{IU} / \mathrm{kg}$ b.i.d. group. These results suggest that the duration of the hypoglycemic condition after $8 \mathrm{hr}$ after administration of the first dose in the $400 \mathrm{IU} / \mathrm{kg}$ b.i.d. group might be longer than those in other treatment groups and excess hypoglycemia induced by fasting might produce mortality only in the $400 \mathrm{IU} / \mathrm{kg}$ b.i.d. group.

The results of the histopathological examination indicated that degeneration of seminiferous tubules in bilateral testes and exfoliation of germ cells in the lumens of bilateral epididymides (secondary changes pursuant to testicular alterations) were observed in the 100, 200, and $400 \mathrm{IU} / \mathrm{kg}$ b.i.d. groups, with the incidences rising with increased doses. These changes were observed in both fasted and non-fasted animals, and appeared to be caused during the treatment period. In a previous study (Mancine et al., 1960), it was reported that testicular changes were observed under severe hypoglycemic conditions that resulted in the induction of coma. In contrast, similar histopathological changes were observed in our study under hypoglycemic conditions that did not produce abnormal clinical findings and body weight changes. In addition to the histopathological changes, sperm analysis of the highest dosage group indicated that the sperm concentration tended to decrease and the incidences of sperm malformations tended to increase. Germ cells need glucose and lactate, which is converted from glucose and is supplied by Sertoli cells. It has been demonstrated that isolated spermatocytes and spermatids degenerated in medium lacking lactate (Jutte et al., 1981), and spermatocytes and spermatids died when seminiferous tubules were incubated in the absence of glucose (Jutte et al., 1982). Thus, insulin-induced hypoglycemia might affect spermatogenesis in this study, resulting in the histopathological and sperm parameter changes.

Table 2. Sperm analysis

\begin{tabular}{lcccc}
\hline Dose (IU/kg b.i.d.) & 0 & 100 & 200 & $400^{\mathrm{a}}$ \\
\hline No. of animals examined & 20 & 20 & 15 & 11 \\
\hline The sperm concentration $\left(\times 10^{6} / \mathrm{mL}\right)$ & $1219 \pm 138$ & $1263 \pm 151$ & $1102 \pm 186$ & $1003 \pm 198$ \\
The incidences of sperm malformations $(\%)^{\mathrm{b}}$ & & & \\
Total & $1.5 \pm 0.9$ & $1.8 \pm 1.2$ & $2.0 \pm 1.4$ & $2.6 \pm 1.3$ \\
Head & $0.3 \pm 0.4$ & $0.5 \pm 0.6$ & $0.6 \pm 0.6$ & $1.0 \pm 0.7$ \\
Neck & $0.9 \pm 0.8$ & $1.1 \pm 0.9$ & $1.2 \pm 1.3$ & $1.4 \pm 1.6$ \\
Middle piece & $0.1 \pm 0.3$ & $0.0 \pm 0.1$ & $0.0 \pm 0.1$ & $0.0 \pm 0.2$ \\
Tail & $0.1 \pm 0.3$ & $0.2 \pm 0.3$ & $0.2 \pm 0.3$ & $0.2 \pm 0.3$ \\
\hline
\end{tabular}

Values are mean \pm S.D.

a: Data were not statistically analyzed.

$\mathrm{b}$ : The incidences were calculated in each region: head, neck, middle piece, and tail. 
The effects of long-lasting hypoglycemia on male reproductive organs

The testicular alterations could be caused by disrupted sex hormone levels. However, this possibility was considered to be low in this study. The weight of the prostate and seminal vesicles is known to be highly sensitive to alterations in hormone concentrations (OECD, 2009; Creasy, 2001; Haschek and Rousseaux, 1998). Nevertheless, no changes in organ weight were observed in this study, which suggests that alterations in sex hormone levels were unlikely to have occurred.

In general, stress produces effects on clinical signs and body weight, and is well known to induce morphological changes in the testis (Greaves, 2007). Nevertheless, abnormal clinical signs and body weight changes were not observed in the animals exhibiting testicular changes. With respect to the localized reddish discoloration observed on the stomach, gastric ulcers are known to be caused by insulin administration to fasted rats (Axelson et al., 1987). It should be noted that the testicular changes were observed irrespective of the observed stomach changes.

In conclusion, our results indicate that long-lasting hypoglycemia affects spermatogenesis and induces histopathological lesions in reproductive organs and abnormalities in germ cells without deterioration of the general condition of rats. Moreover, our results suggest that it is important to pay attention to the possible secondary changes to male reproductive organs caused by hypoglycemia when evaluating the toxicological effects of hypoglycemic agents.

\section{ACKNOWLEDGMENTS}

The authors wish to thank all members of the toxicology research department, Pharmaceutical Development Research Laboratories, Teijin Pharma Limited, for their help and support during this study.

Conflict of interest---- The authors declare that there is no conflict of interest.

\section{REFERENCES}

Axelson, J., Håkanson, R. and Hedenbro, J.L. (1987): Insulin-induced gastric ulcers in the rat. Scand. J. Gastroenterol., 22, 737742.

Bajpai, M., Gupta, G. and Setty, B.S. (1998): Changes in carbohydrate metabolism of testicular germ cells during meiosis in the rat. Eur. J. Endocrinol., 138, 322-327.

Bensoussan, K., Morales, C.R. and Hermo, L. (1998): Vitamin E deficiency causes incomplete spermatogenesis and affects the structural differentiation of epithelial cells of the epididymis in the rat. J. Androl., 19, 266-288.

Bonds, D.E., Miller, M.E., Bergenstal, R.M., Buse, J.B., Byington, R.P., Cutler, J.A., Dudl, R.J., Ismail-Beigi, F., Kimel, A.R.,
Hoogwerf, B., Horowitz, K.R., Savage, P.J., Seaquist, E.R., Simmons, D.L., Sivitz, W.I., Speril-Hillen, J.M. and Sweeney, M.E. (2010): The association between symptomatic, severe hypoglycaemia and mortality in type 2 diabetes: retrospective epidemiological analysis of the ACCORD study. Br. Med. J., 340, b4909.

Boussouar, F. and Benahmed, M. (2004): Lactate and energy metabolism in male germ cells. Trends Endocrinol. Metab., 15, 345350 .

Creasy, D.M. (2001): Pathogenesis of male reproductive toxicity. Toxicol. Pathol., 29, 64-76.

Greaves, P. (2007): Male Genital Tract, In Histopathology of Preclinical Toxicity Studies, pp.661-716, Elsevier.

Haschek, W.M. and Rousseaux, C.G. (1998): Male Reproductive System, In Fundamentals of Toxicologic Pathology, pp.443-484, Academic Press, San Diego.

ICH (2005): Harmonised Tripartite Guideline S5(R2). Detection of toxicity to reproduction for medicinal products \& toxicity to male fertility.

Jutte, N.H., Grootegoed, J.A., Rommerts, F.F., and van der Molen, H.J. (1981): Exogenous lactate is essential for metabolic activities in isolated rat spermatocytes and spermatids. J. Reprod. Fertil., 62, 399-405.

Jutte, N.H., Jansen, R., Grootegoed, J.A., Rommerts, F.F., Clausen, O.P. and van der Molen, H.J. (1982): Regulation of survival of rat pachytene spermatocytes by lactate supply from Sertoli cells. J. Reprod. Fertil., 65, 431-438.

Livera, G., Rouiller-Fabre, V., Pairault, C., Levacher, C. and Habert, R. (2002): Regulation and perturbation of testicular functions by vitamin A. Reproduction, 124, 173-180.

Mancine, R.E., Penhos, J.C., Izquierdo, I.A. and Heinrich, J.J. (1960): Effects of acute hypoglycemia on rat testis. Proc. Soc. Exp. Biol. Med., 104, 699-702.

Mason, K.E., Burns, W.A. and Smith, J.C.Jr. (1982): Testicular damage associated with zinc deficiency in pre- and postpubertal rats: response to zinc repletion. J. Nutr., 112, 1019-1028.

Merker, H.J. and Günther, T. (1997): Testis damage induced by zinc deficiency in rats. J. Trace Elem. Med. Biol., 11, 19-22.

OECD (2008): OECD Guideline for Testing of Chemicals. Repeated Dose 28-Day Oral Toxicity Study in Rodents. TG 407.

OECD (2009): Guidance document for histologic evaluation of endocrine and reproductive tests in rodents, OECD Environment, Health and Safety Publications, Series on Testing and Assessment No. 106, ENV/JM/MONO(2009)11.

Rato, L., Alves, M.G., Socorro, S., Duarte, A.I., Cavaco, J.E. and Oliveira, P.F. (2012): Metabolic regulation is important for spermatogenesis. Nat. Rev. Urol., 9, 330-338.

Robinson, R. and Fritz, I.B. (1981): Metabolism of glucose by Sertoli cells in culture. Biol. Reprod., 24, 1032-1041.

Rosenstock, J., Schwartz, S.L., Clark, C.M.Jr., Park, G.D., Donley, D.W. and Edwards, M.B. (2001): Basal insulin therapy in type 2 diabetes: 28-week comparison of insulin glargine (HOE 901) and NPH insulin. Diabetes Care, 24, 631-636.

Sobhon, P., Mitranond, V., Tosukhowong, P. and Chindaduangrat, W. (1979): Cytological changes in the testes of vitamin-A-deficient rats. II. Ultrastructural study of the seminiferous tubules. Acta Anat., 103, 169-183.

Yki-Järvinen, H., Dressler, A., Ziemen, M. and HOE 901/300s Study Group. (2000): Less nocturnal hypoglycemia and better post-dinner glucose control with bedtime insulin glargine compared with bedtime NPH insulin during insulin combination therapy in type 2 diabetes. Diabetes Care, 23, 1130-1136. 